\title{
Article \\ Polydopamine Doping and Pyrolysis of Cellulose Nanofiber Paper for Fabrication of Three-Dimensional Nanocarbon with Improved Yield and Capacitive Performances
}

\author{
Luting Zhu *(D), Kojiro Uetani (), Masaya Nogi and Hirotaka Koga *(D) \\ SANKEN (The Institute of Scientific and Industrial Research), Osaka University, 8-1 Mihogaoka, \\ Ibaraki 567-0047, Osaka, Japan; uetani@eco.sanken.osaka-u.ac.jp (K.U.); nogi@eco.sanken.osaka-u.ac.jp (M.N.) \\ * Correspondence: sharollzhu@eco.sanken.osaka-u.ac.jp (L.Z.); hkoga@eco.sanken.osaka-u.ac.jp (H.K.); \\ Tel.: +81-6-6879-8442 (L.Z. \& H.K.)
}

\section{check for} updates

Citation: Zhu, L.; Uetani, K.; Nogi, M.; Koga, H. Polydopamine Doping and Pyrolysis of Cellulose Nanofiber Paper for Fabrication of Three-Dimensional Nanocarbon with Improved Yield and Capacitive Performances. Nanomaterials 2021, 11, 3249. https://doi.org/10.3390/ nano11123249

Academic Editors: Wei Zhang and Vijay Kumar Thakur

Received: 2 November 2021 Accepted: 26 November 2021 Published: 30 November 2021

Publisher's Note: MDPI stays neutral with regard to jurisdictional claims in published maps and institutional affiliations.

Copyright: (c) 2021 by the authors. Licensee MDPI, Basel, Switzerland. This article is an open access article distributed under the terms and conditions of the Creative Commons Attribution (CC BY) license (https:/ / creativecommons.org/licenses/by/ $4.0 /)$.
Abstract: Biomass-derived three-dimensional (3D) porous nanocarbons have attracted much attention due to their high surface area, permeability, electrical conductivity, and renewability, which are beneficial for various electronic applications, including energy storage. Cellulose, the most abundant and renewable carbohydrate polymer on earth, is a promising precursor to fabricate 3D porous nanocarbons by pyrolysis. However, the pyrolysis of cellulosic materials inevitably causes drastic carbon loss and volume shrinkage. Thus, polydopamine doping prior to the pyrolysis of cellulose nanofiber paper is proposed to fabricate the 3D porous nanocarbons with improved yield and volume retention. Our results show that a small amount of polydopamine ( $4.3 \mathrm{wt} \%$ ) improves carbon yield and volume retention after pyrolysis at $700{ }^{\circ} \mathrm{C}$ from 16.8 to $26.4 \%$ and 15.0 to $19.6 \%$, respectively. The pyrolyzed polydopamine-doped cellulose nanofiber paper has a larger specific surface area and electrical conductivity than cellulose nanofiber paper that without polydopamine. Owing to these features, it also affords a good specific capacitance up to $200 \mathrm{~F} \mathrm{~g}^{-1}$ as a supercapacitor electrode, which is higher than the recently reported cellulose-derived nanocarbons. This method provides a pathway for the effective fabrication of high-performance cellulose-derived 3D porous nanocarbons.

Keywords: polydopamine doping; cellulose nanofiber; pyrolysis; 3D porous nanocarbon; supercapacitor

\section{Introduction}

There has been rapid progress in the fabrication and design of three-dimensional (3D) porous nanocarbon materials because they provide several advantages such as high surface areas, short diffusion spaces for fast reaction kinetics, and efficient electron pathways [1,2]. As a result, 3D porous nanocarbons have been actively investigated for energy storage applications [3-5], including supercapacitors [6,7] and batteries [8-10].

The majority of carbon-based materials have been conventionally fabricated using petroleum-based precursors [11]. For example, carbon nanofibers have been produced from polyacrylonitrile, pitches, and phenolic resins [12], while commercial carbon fibers, including carbon nanofibers, are produced from petroleum-based precursors only [13], more than $96 \%$ of commercial carbon fibers are made from polyacrylonitrile [13,14]. From the viewpoint of sustainable development, there has been an increased demand to replace these non-renewable petroleum-based precursors with abundant and renewable precursors $[15,16]$. Therefore, renewable biomass-derived 3D porous nanocarbons have been actively developed [17-20].

Cellulose, which is directly produced from natural plants, is known as the most abundant and renewable carbohydrate polymer on earth [21]. Cellulose intrinsically exists in the plant cell wall [22], and it can be extracted in the form of nanofibers by physical and/or chemical methods [23-25]. Because plant-derived cellulose nanofibers can be fabricated into paper with $3 \mathrm{D}$ porous nanostructures by the solvent exchange and papermaking 
processes [26,27], cellulose nanofiber paper may be a promising precursor to the fabrication of $3 \mathrm{D}$ porous nanocarbons by pyrolysis. Cellulose possesses the theoretical carbon content of $44.4 \mathrm{wt} \%$, which refers to the residual six carbon atoms per anhydroglucose unit in the cellulose molecular structure [28]. However, the pyrolysis of cellulose is inevitably accompanied by combustion reactions, forming volatile low-molecular-weight carbon-containing substances such as $\mathrm{CO}, \mathrm{CO}_{2}$, alcohols, and ketones and resulting in low yield and drastic volume shrinkage $[28,29]$. Thus, it is a challenge to fabricate cellulose-derived 3D porous nanocarbons with improved yield and volume retention.

Thus, in this study, polydopamine doping prior to the pyrolysis of the cellulose nanofiber paper is proposed. The small amount of dopamine, which is a well-known biomolecule that is present in various animals [30] is polymerized in situ in the cellulose nanofiber suspension, and it is then fabricated into paper with 3D porous nanostructures. The resulting polydopamine-doped cellulose nanofiber paper is pyrolyzed to prepare the 3D porous nanocarbon with improved yield and volume retention compared to that pyrolyzed without polydopamine doping. Furthermore, polydopamine doping also yields cellulose nanofiber papers with enhanced specific surface areas and electrical conductivity, thereby providing high capacitive performances for energy storage applications.

\section{Materials and Methods}

\subsection{Materials}

Cellulose nanofiber water suspension (BiNFi-s cellulose, raw material: softwood bleached kraft pulp) was obtained from Sugino Machine Ltd., Toyama, Japan. Dopamine hydrochloride, tert-butyl alcohol, tris(hydroxymethyl)aminomethane, potassium hydroxide, and $0.5 \mathrm{M}$ hydrochloric acid solution were obtained from Nacalai Tesque, Inc., Kyoto, Japan. All chemicals were of analytical reagent grade and were used without further purification.

\subsection{In Situ Polymerization of Dopamine in Cellulose Nanofiber Suspension}

In situ polymerization of dopamine in the cellulose nanofiber suspension was performed according to a previous report [31]. Briefly, $0.24 \mathrm{~g}$ tris(hydroxymethyl)aminomethane was first added to cellulose nanofiber water suspension $(0.2 \mathrm{wt} \%, 200 \mathrm{~mL})$, and the $\mathrm{pH}$ was adjusted to 8.0 by means of a $0.5 \mathrm{M}$ hydrochloric acid solution. Then, different amounts of dopamine hydrochloride $(0.025 \mathrm{~g}, 0.05 \mathrm{~g}$, and $0.1 \mathrm{~g})$ were mixed with the suspension, and the suspension was then stirred for 1 day at approximately $25^{\circ} \mathrm{C}$. The suspension turned black in color during the dopamine polymerization [32,33].

Neat polydopamine was also prepared by adding $0.24 \mathrm{~g}$ tris(hydroxymethyl)aminomethane to $200 \mathrm{~mL}$ distilled water and by adjusting the $\mathrm{pH}$ to 8.0 with $0.5 \mathrm{M}$ hydrochloric acid followed by adding $0.1 \mathrm{~g}$ dopamine hydrochloride and stirring the mixture for 1 day at approximately $25^{\circ} \mathrm{C}$. Subsequently, the suspension was centrifugated at 10,000 rpm for 15 min (Model 7000, Kubota Corporation Co., Ltd., Tokyo, Japan). The precipitate was washed with distilled water, and it was then centrifuged in the same conditions; this washing treatment was repeated three times. Finally, the polydopamine was dispersed in distilled water and frozen overnight in a refrigerator (SJ-23T, Sharp Corp., Osaka, Japan) and freeze dried (EYELA FDU-2200, Tokyo Rikakikai Co., Ltd., Tokyo, Japan).

\subsection{Preparation of Polydopamine-Doped Cellulose Nanofiber Papers}

The aqueous mixture of polydopamine and cellulose nanofibers was dewatered by suction filtration (KST-47, Advantec Toyo Kaisha, Ltd., Tokyo, Japan) through a commercial membrane filter (H020A090C, hydrophilic polytetrafluoroethylene membrane with pore size of $0.2 \mu \mathrm{m}$, Advantec Toyo Kaisha, Ltd., Tokyo, Japan). Then, $200 \mathrm{~mL}$ distilled water was gently added onto the wet sheet, and it was then vacuum filtrated to remove excess reagents. To form the 3D porous nanostructures [27,34], $200 \mathrm{~mL}$ of tert-butyl alcohol was further added, followed by vacuum filtration. The obtained wet paper was then peeled off from the filter, stored at approximately $-18{ }^{\circ} \mathrm{C}$ for over $2 \mathrm{~h}$ in a refrigerator, and freeze-dried to prepare the polydopamine-doped cellulose nanofiber papers. 


\subsection{Pyrolysis of Polydopamine-Doped Cellulose Nanofiber Papers}

The polydopamine-doped cellulose nanofiber papers were cut into square-shaped samples with the size of $1.5 \times 1.5 \mathrm{~cm}^{2}$, followed by pyrolysis at $700{ }^{\circ} \mathrm{C}$ for $1 \mathrm{~h}$ under $\mathrm{N}_{2}$ gas using a desktop gas convertible vacuum furnace (KDF75, Denken-Highdental Co., Ltd., Kyoto, Japan). The heating and cooling rates were set at $2{ }^{\circ} \mathrm{C} \mathrm{min}^{-1}$. The $\mathrm{N}_{2}$ flux was set at $0.5 \mathrm{~L} \mathrm{~min}^{-1}$. The weight and volume of the original and polydopaminedoped cellulose nanofiber papers were measured before and after pyrolysis. To calculate the weight and volume retention after pyrolysis, five pieces of the paper samples were prepared for each polydopamine content. The polydopamine particles were also pyrolyzed under the same conditions. To calculate the weight retention after pyrolysis, three batches of the polydopamine particles were prepared.

\subsection{Electrochemical Tests as Supercapacitor Electrodes}

The electrochemical tests as a supercapacitor electrode were performed by a threeelectrode system using $6 \mathrm{M} \mathrm{KOH}$ aqueous electrolyte (ModuLab XM, Solartron AnalyticalAMETEK Advanced Measurement Technology Inc., Berkshire, UK). Approximately 2-5 mg pyrolyzed polydopamine-doped cellulose nanofiber paper was directly evaluated as a working electrode, which was covered by nickel foam for electrical signal collection. A $\mathrm{Hg} / \mathrm{HgO}$ electrode was used as the reference electrode. A platinum wire was used as the counter electrode. Galvanostatic charge/discharge tests and the cyclic voltammetry $(\mathrm{CV})$ were operated at the current densities of $0.5-20 \mathrm{~A} \mathrm{~g}^{-1}$ and the scan rate of $10 \mathrm{mV} \mathrm{s}^{-1}$, respectively. Electrochemical impedance spectroscopy (EIS) was measured in the frequency range from 0.1 to $100 \mathrm{kHz}$, with an amplitude of $5 \mathrm{mV}$. A single-electrode gravimetric capacitance $\left(C, \mathrm{~F} \mathrm{~g} \mathrm{~g}^{-1}\right)$ was estimated by the following formula, according to charge/discharge curves:

$$
C=I D t /(m \Delta V)
$$

where $I$ and $D t$ are the charge/discharge current (A) and the discharge time (s), respectively, $m$ is the weight $(\mathrm{g})$ of the pyrolyzed polydopamine-doped cellulose nanofiber paper, and $\Delta V$ is the voltage change $(V)$, which excluded the internal resistance drop in the discharge period.

\subsection{Characterization}

Thermogravimetric (TG) analyses were carried out under a nitrogen flux of $60 \mathrm{~mL} \mathrm{~min}^{-1}$ at a heating rate of $10^{\circ} \mathrm{C} \mathrm{min}^{-1}$ (TGA Q50N2, TA Instruments, New Castle, DE, USA), with approximately $15 \mathrm{mg}$ sample placed in the platinum pan. The surface and cross-section observations were performed using field-emission scanning electron microscopy (FE-SEM) (SU-8020, Hitachi High-Tech Science Corp., Tokyo, Japan). The acceleration voltage was set at $2 \mathrm{kV}$. Before the FE-SEM observation, platinum sputtering was performed on the samples at $20 \mathrm{~mA}$ for $10 \mathrm{~s}$. The nitrogen physisorption measurements were operated at $77 \mathrm{~K}$ (NOVA 4200e, Quantachrome Instruments, Kanagawa, Japan). Brunauer-Emmett-Teller (BET) analyses were carried out at relative pressures ranging from 0.01 to 0.3 . X-ray diffraction (XRD) analysis was performed by means of an Ultima IV X-ray diffractometer (Rigaku Corp., Tokyo, Japan) with Ni-filtered $\mathrm{Cu} \mathrm{K} \alpha$ radiation (1.5418 $\AA$ ) at $40 \mathrm{kV}$ and $40 \mathrm{~mA}$, and the scanning angle $(2 \theta)$ was from $5^{\circ}$ to $80^{\circ}$ at the scanning rate of $1^{\circ} \mathrm{min}^{-1}$. Raman spectra were recorded at a laser wavelength and a power of $532 \mathrm{~nm}$ and $0.1 \mathrm{~mW}$, respectively (RAMAN-touch VIS-NIR-OUN, Nanophoton Corp., Osaka, Japan). Elemental analysis was operated by a JM10 instrument (J-Science Lab Co., Ltd., Kyoto, Japan). The volume resistivity measurements were performed by a four-probe resistivity meter (Loresta-GP, MCP-T610, Mitsubishi Chemical Analytech Co., Ltd., Tokyo, Japan); three pieces of the pyrolyzed polydopamine-doped cellulose nanofiber papers were prepared for each polydopamine content, and three different positions were measured for each paper sample. 


\section{Results}

\subsection{Pyrolysis of Polydopamine-Doped Cellulose Nanofiber Paper}

Polydopamine doping and the pyrolysis of the cellulose nanofiber paper were performed as shown in Figure 1. In brief, different amounts of dopamine were first added to the cellulose nanofiber suspension for in situ polymerization to polydopamine. Then, the black-colored aqueous dispersion of the polydopamine-doped cellulose nanofibers was dewatered by suction filtration and solvent exchange, and the samples were then freeze dried. As such, cellulose nanofiber papers with different polydopamine contents $\left(3.4-8.2 \mathrm{wt} \%\right.$ ) were obtained (Supplementary Figure S1) and pyrolyzed at $700{ }^{\circ} \mathrm{C}$.

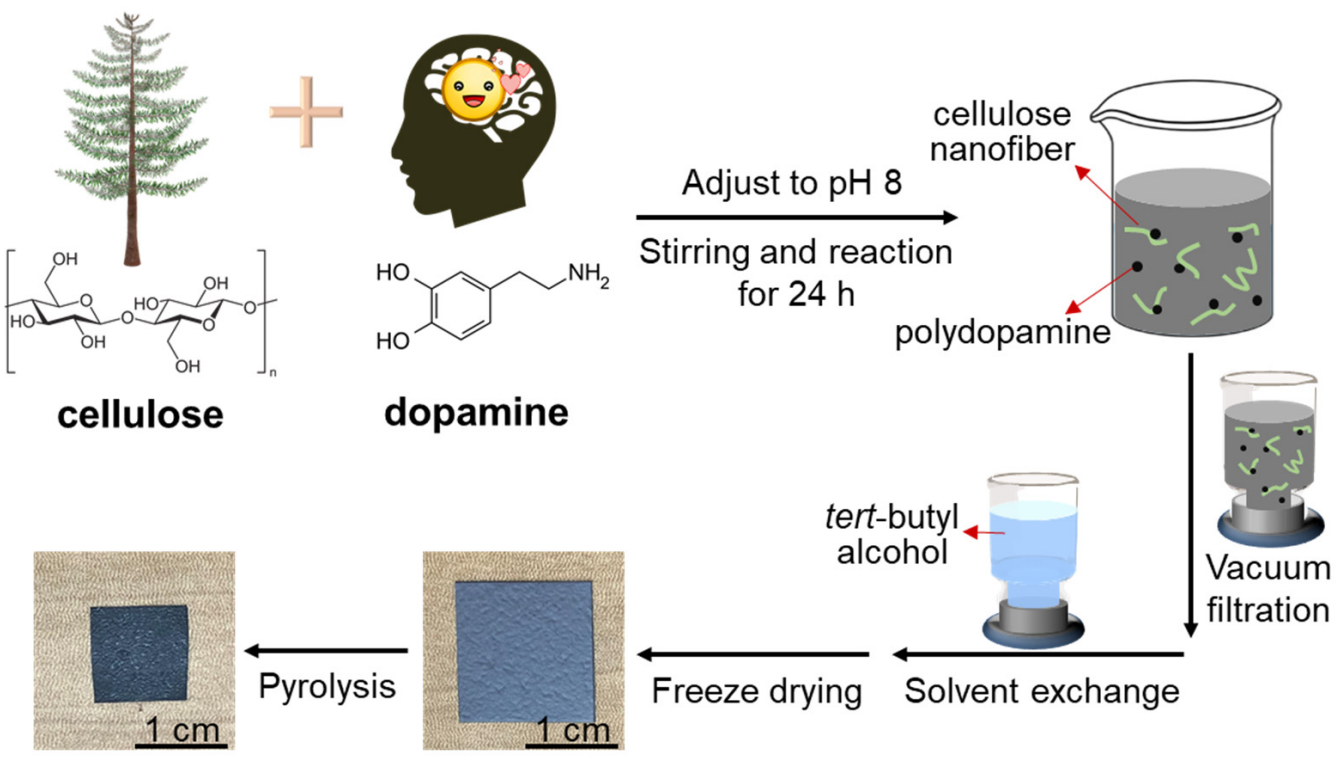

Figure 1. Schematic illustration of the sequential procedure for polydopamine doping and pyrolysis of the cellulose nanofiber paper.

As shown in Figure 2a, the original and polydopamine-doped cellulose nanofiber papers shrank and became brittle to some degree after pyrolysis, but the papers were freestanding, which enabled them to be handled easily for characterization and application testing. Notably, polydopamine doping improved the volume retention (from 15.0\% to $23.6 \%$ ) (Figure $2 \mathrm{~b}$ ), weight retention (from $8.6 \%$ to $14.6 \%$ ) (Figure $2 \mathrm{c}$ ), and carbon yield (from $16.8 \%$ to $28.9 \%$ ) (Figure 2d, see also Figure S2) of the pyrolyzed cellulose nanofiber paper. Moreover, the weight retention and carbon yield of the pyrolyzed polydopaminedoped cellulose nanofiber paper were higher than the estimated ones. For example, the weight retention and carbon yield of the $4.3 \mathrm{wt} \%$ polydopamine-doped cellulose nanofiber paper after pyrolysis were $13.0 \%$ and $26.4 \%$, respectively, which were higher than those $(10.9 \%$ and $19.8 \%$, respectively) estimated from the original cellulose nanofiber paper and neat polydopamine after pyrolysis. Because the polydopamine content was low, it can be expected that the increased weight retention and carbon yield are mainly due to the weight retention of cellulose.

To explain the improved weight and volume retention by polydopamine doping, the TG and derivative thermogravimetric (DTG) curves were analyzed. As it can be seen in Figure 2e, the thermal decomposition temperature $(5 \%$ weight decrease in the TG curves [35]) of the original cellulose nanofiber paper increased after polydopamine doping from $268.3{ }^{\circ} \mathrm{C}$ (polydopamine: $0 \mathrm{wt} \%$ ) to $282.8(3.4 \mathrm{wt} \%), 279.3\left(4.3 \mathrm{wt} \%\right.$ ), and $277.8^{\circ} \mathrm{C}$ $(8.2 \mathrm{wt} \%)$, while that of neat polydopamine was $220.2^{\circ} \mathrm{C}$. The DTG peak temperature and derivative weight of the cellulose nanofiber paper decreased when the polydopamine content increased (Figure 2f). These results suggested that polydopamine doping improves the thermal stability of the cellulose nanofiber paper, thereby affording the increased weight yield and volume. The improved thermal stability can be ascribed to the radical scavenging 
effect of the catecholic compounds (e.g., polydopamine [36] and melanin [37]). While free radicals, which are generated from cellulose during pyrolysis, unfavorably generate gaseous compounds to cause large weight loss [38], polydopamine can scavenge some of these free radicals and can suppress the weight loss.

(a)

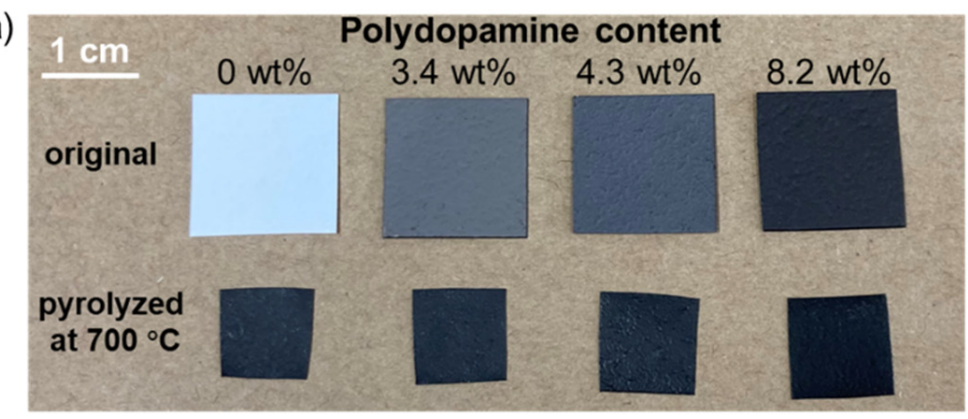

(b)

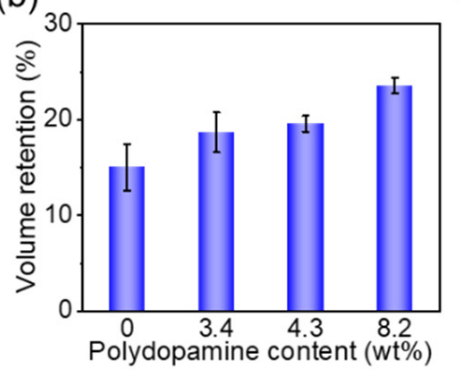

(c)

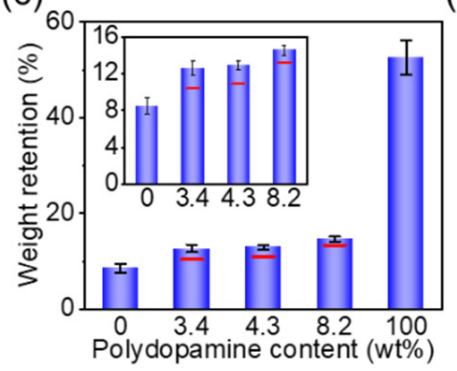

(d)

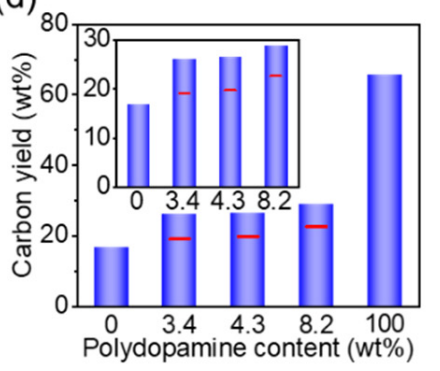

(e)
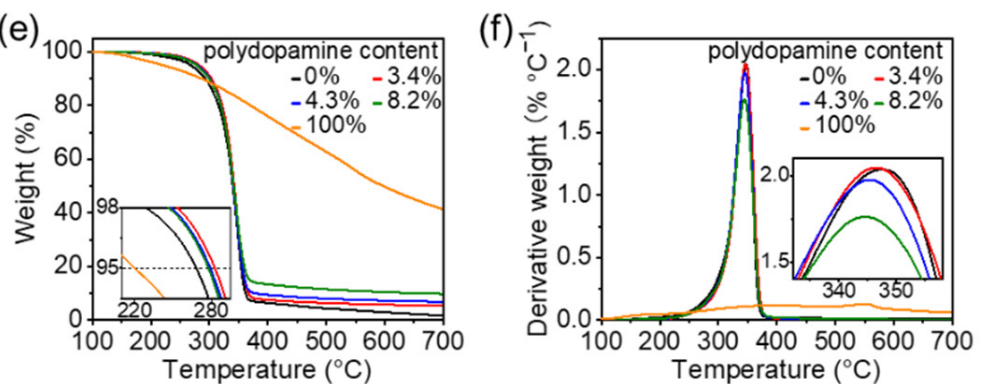

Figure 2. Pyrolysis of the polydopamine-doped cellulose nanofiber paper. (a) Cellulose nanofiber papers with different polydopamine contents before and after pyrolysis at $700{ }^{\circ} \mathrm{C} ;(\mathbf{b})$ volume retention and (c) weight retention (the red lines indicate the weight retention estimated from the original cellulose and neat polydopamine) and (d) carbon yield (the red lines indicate the carbon yield estimated from the pyrolyzed cellulose and pyrolyzed polydopamine) of the pyrolyzed cellulose nanofiber papers with different polydopamine contents; (e) thermogravimetric and (f) derivative thermogravimetric curves of the cellulose nanofiber papers with different polydopamine contents and neat polydopamine.

\subsection{D Porous Nanostructures of Pyrolyzed Polydopamine-Doped Cellulose Nanofiber Paper}

The 3D porous nanostructures provide unique properties, including high surface areas and permeability, which are beneficial for a variety of applications including energy storage. Therefore, the $3 \mathrm{D}$ porous nanostructures of the original and the pyrolyzed polydopaminedoped cellulose nanofiber papers were analyzed accordingly (Figure 3). The undoped cellulose nanofiber paper with a thickness of approximately $270 \mu \mathrm{m}$ contained a porous nanofiber network (Figure 3a) and a layered structure (Figure S3), comprising the 3D porous nanostructures. The occurrence of these 3D porous nanostructures can be ascribed to the solvent exchange from water to tert-butyl alcohol during the paper fabrication process because the tert-butyl alcohol with low surface tension suppressed the aggregation of the cellulose nanofibers upon drying [27]. 
(a)

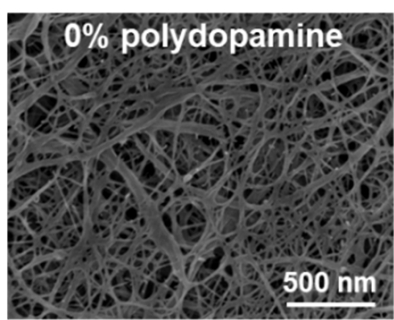

(e)

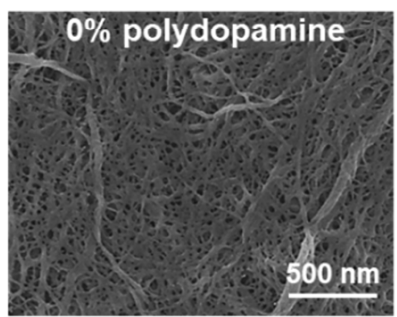

(i)

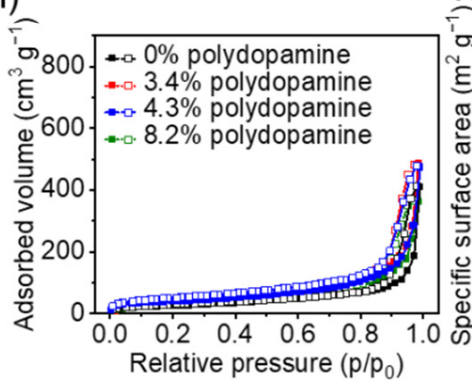

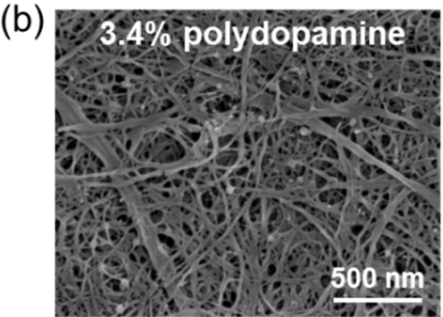

(f)

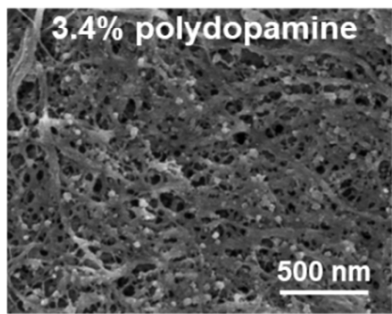

(c)

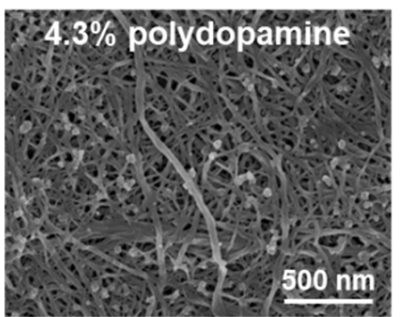

(g)

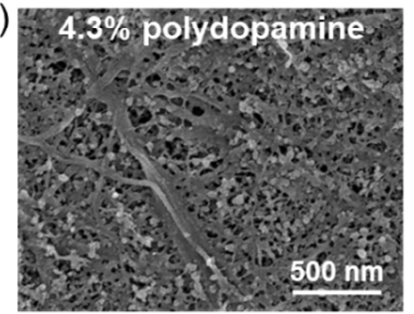

(d) $8.2 \%$ poly ofopamine

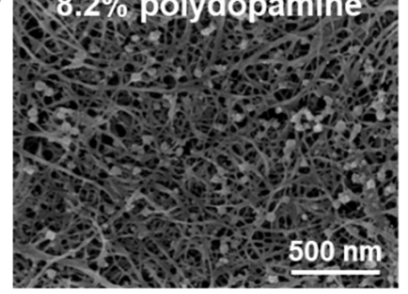

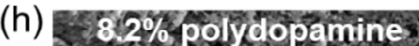

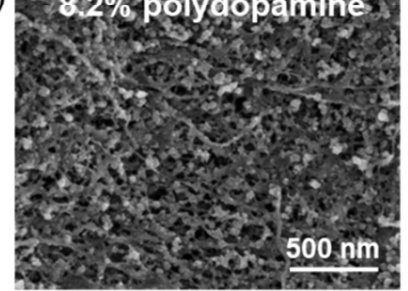

After pyrolysis

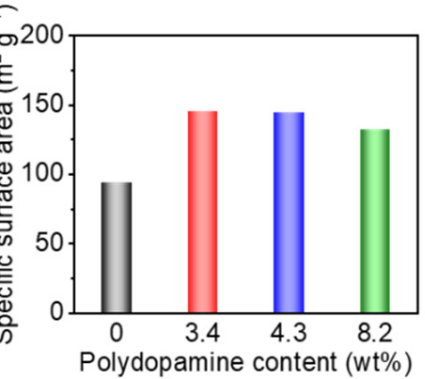

(j)

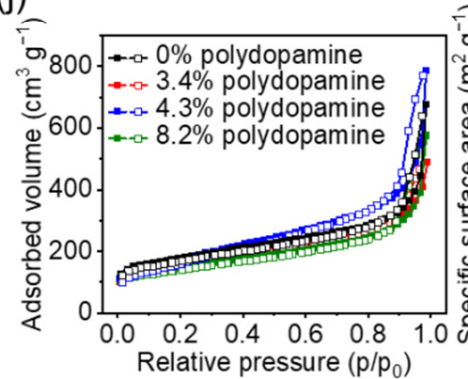

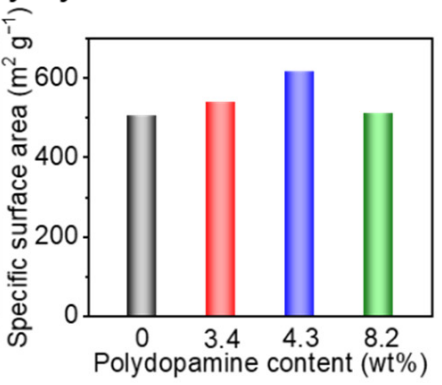

Figure 3. Three-dimensional porous nanostructures of pyrolyzed polydopamine-doped cellulose nanofiber papers. Field emission scanning electron microscopy images of the cellulose nanofiber papers with different polydopamine content (a-d) before and (e-h) after pyrolysis at $700{ }^{\circ} \mathrm{C} ; \mathrm{N}_{2}$ adsorption and desorption isotherms of cellulose nanofiber papers with different polydopamine content and the corresponding specific surface areas (i) before and (j) after pyrolysis at $700{ }^{\circ} \mathrm{C}$.

Further, the 3D porous nanostructures were maintained even after polydopamine doping (Figure 3b-d and Figure S3). The polydopamine particles formed by in situ polymerization in the cellulose nanofibers had a diameter $\leq \sim 50 \mathrm{~nm}$ (Figure $3 \mathrm{~b}-\mathrm{d}$ ), which was much smaller than the neat polydopamine nanoparticles prepared in the absence of cellulose nanofibers (Figure S4), suggesting that cellulose nanofibers can restrict the growth and aggregation of the polydopamine nanoparticles. Owing to the nanosized polydopamine particles, the polydopamine-doped cellulose nanofiber papers had a higher specific surface area $\left(132-145 \mathrm{~m}^{2} \mathrm{~g}^{-1}\right)$ than the original $\left(94 \mathrm{~m}^{2} \mathrm{~g}^{-1}\right)$ (Figure $3 \mathrm{i}$ ).

It was also confirmed that the polydopamine-doped cellulose nanofiber papers maintained their 3D porous nanostructures after pyrolysis at $700{ }^{\circ} \mathrm{C}$ (Figure $3 \mathrm{e}-\mathrm{h}$ and Figure S3). The thicknesses of the pyrolyzed polydopamine-doped cellulose nanofiber papers were approximately $108,112,129$, and $142 \mu \mathrm{m}$ at a polydopamine content of $0 \%, 3.4 \%, 4.3 \%, 8.2 \%$, respectively. The $\mathrm{N}_{2}$ adsorption and desorption isotherms of the pyrolyzed polydopaminedoped cellulose nanofiber papers indicated an obvious increase of $\mathrm{N}_{2}$ adsorption in the low relative pressure range and a hysteresis loop in the high relative pressure range, suggesting the presence of micropores $(<2 \mathrm{~nm})$ and mesopores $(2-50 \mathrm{~nm}$, characteristic of type IV isotherm), respectively [39,40]. The $4.3 \mathrm{wt} \%$ polydopamine-doped cellulose nanofiber paper showed the highest specific surface area $\left(617 \mathrm{~m}^{2} \mathrm{~g}^{-1}\right)$ after pyrolysis, which was much larger than that without polydopamine doping $\left(506 \mathrm{~m}^{2} \mathrm{~g}^{-1}\right)$. However, at $8.2 \mathrm{wt} \%$ polydopamine, a lower specific surface area $\left(510 \mathrm{~m}^{2} \mathrm{~g}^{-1}\right)$ after pyrolysis was observed, suggesting that the excess amount of polydopamine decreases the resulting specific surface area. The appropriate amount of polydopamine nanoparticles within the cellulose nanofiber paper partially restrain the shrinkage of the porous nanofiber networks upon pyrolysis and provide higher volume retention and specific surface areas (see also 
Figure $2 b$ ), while an excess amount of polydopamine nanoparticles may block the porous nanostructures, thereby decreasing the specific surface areas. Our results indicate that 3D porous nanostructures with high specific surface areas can be obtained after the pyrolysis of appropriately polydopamine-doped cellulose nanofiber paper.

\subsection{Molecular Structure and Electrical Conductivity of Pyrolyzed Polydopamine-Doped Cellulose Nanofiber Papers}

The chemical structures and electrical properties of the pyrolyzed polydopaminedoped cellulose nanofiber papers were also analyzed (Figure 4). The Raman spectra showed the $G$ band at approximately $1580 \mathrm{~cm}^{-1}$ and D band at approximately $1340 \mathrm{~cm}^{-1}$, which are ascribed to the graphitic carbon domains and the disordered graphitic carbon structures (e.g., edge of graphitic domains and in-plane imperfections) [41], respectively (Figure 4a). This indicates the formation of graphitic carbon structures with disordered regions, such as oxygen- and nitrogen-doped carbon structures, as a result of pyrolysis (see also Figure S2). The graphitic structures after pyrolysis were also confirmed by the XRD spectra. Broad peaks at approximately $23^{\circ}$ and $43^{\circ}$ (Figure $4 \mathrm{~b}$ ) were observed, which are assigned to the (002) and (10) bands of graphite, respectively [42,43]. The crystallite sizes in the inplane $\left(L_{a}\right)$ and stacking $\left(L_{c}\right)$ directions of the graphitic carbon can be estimated using Scherrer's formula from the (10) and (002) lattice planes, respectively [41,43]. As shown in Figure $4 \mathrm{c}$, the graphitic carbon domains increased their average width $\left(L_{a}\right)$ from $\sim 1.9$ to $2.4 \mathrm{~nm}$ (interplanar distance $d a=\sim 0.2 \mathrm{~nm}$ ) with increasing polydopamine content, while their average thickness $\left(L_{c}\right)$ was almost constant at $\sim 1.0 \mathrm{~nm}$. Because neat polydopamine pyrolyzed at the same temperature $\left(700{ }^{\circ} \mathrm{C}\right)$ showed a lower average width of $\sim 1.7 \mathrm{~nm}$ than the pyrolyzed polydopamine-doped cellulose nanofiber papers, it was suggested that the combination of polydopamine and cellulose nanofibers can promote the growth of the graphitic carbon domains in the in-plane direction after pyrolysis. Such promoted growth of electrically conductive graphitic carbon domains also contributed toward the increased electrical conductivity (decreased volume resistivity); the volume resistivities of the pyrolyzed polydopamine-doped cellulose nanofiber papers decreased from 8.8 to $5.5 \Omega \mathrm{cm}$ when the polydopamine content increased (Figure $4 \mathrm{~d}$ ), indicating high electrical conductivity and the positive effect of polydopamine doping.

\subsection{Application as an Electrode for a Supercapacitor}

Tuning the porous structure and molecular structure of cellulose-derived nanocarbons by doping is effective in enhancing their energy storage performance [44-46]. To demonstrate the significance of the polydopamine doping and pyrolysis of the cellulose nanofiber paper, the pyrolyzed polydopamine-doped cellulose nanofiber paper was applied as a supercapacitor electrode in a $6 \mathrm{M} \mathrm{KOH}$ aqueous electrolyte with a three-electrode system. The previously reported cellulose-derived porous carbons frequently required additives, such as conductive carbon and binder [47-49]. On the other hand, our pyrolyzed polydopamine-doped cellulose nanofiber papers were successfully applied as conductive and free-standing electrodes. Such free-standing property can ensure sufficient transportation of electrons and electrolyte ions between the current collector and the electrodes [50]. The pyrolyzed polydopamine-doped cellulose nanofiber papers showed a larger surrounding area of the CV curve and longer discharge time in the galvanostatic charge/discharge curve than those without polydopamine doping, indicating the higher capacitance of the pyrolyzed polydopamine-doped cellulose nanofiber papers (Figure 5a,b). The specific capacitance values were plotted as a function of the current densities based on the charge-discharge curves (Figure 5c). Notably, the pyrolyzed $4.3 \mathrm{wt} \%$ polydopamine-doped cellulose nanofiber paper showed the highest specific capacitance of up to approximately $200 \mathrm{~F} \mathrm{~g}^{-1}$ at current densities of $0.5-20 \mathrm{~A} \mathrm{~g}^{-1}$, which was considerably higher than that without polydopamine doping (approximately $160 \mathrm{~F} \mathrm{~g}^{-1}$ ). 
(a)

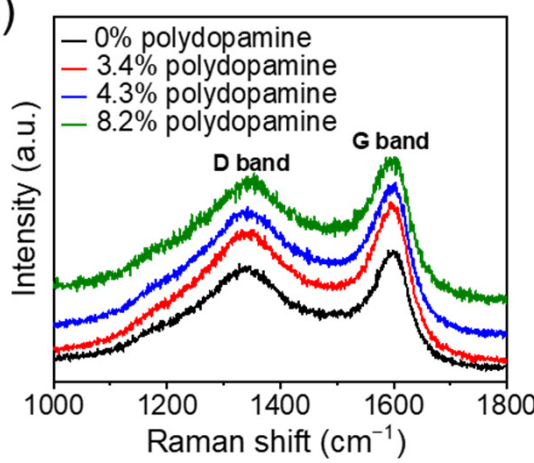

(c)

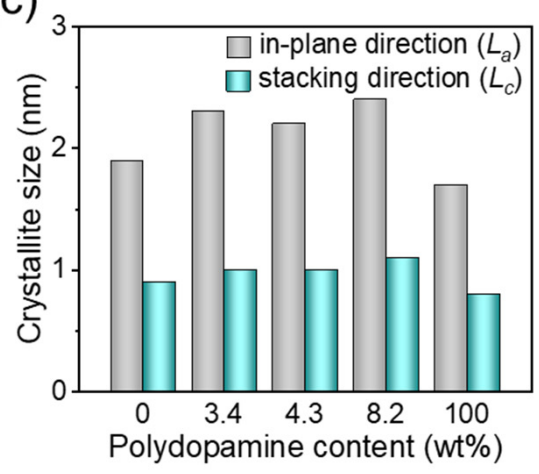

(b)

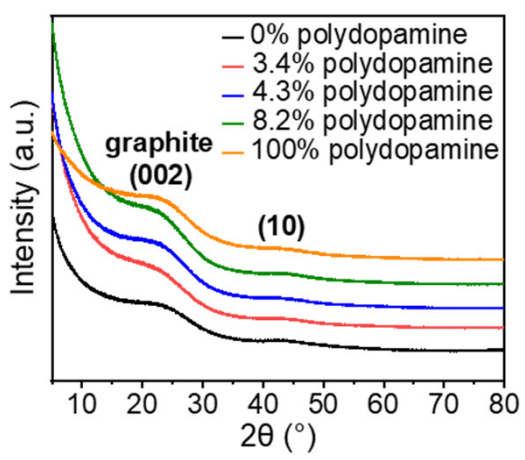

(d)

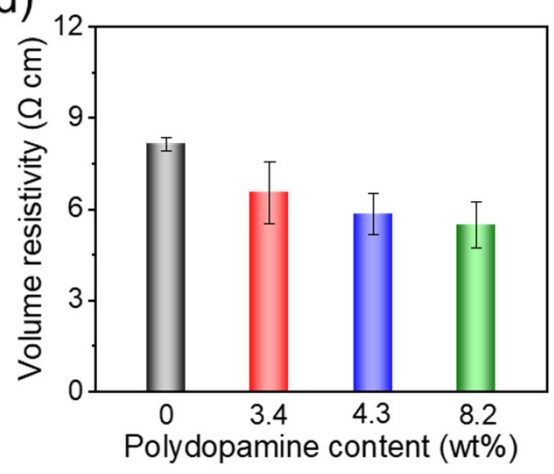

Figure 4. Molecular structure and electrical conductivity of the polydopamine-doped cellulose nanofiber papers pyrolyzed at $700{ }^{\circ} \mathrm{C}$. (a) Raman spectra, (b) X-ray diffraction spectra, (c) crystallite sizes of the graphitic carbon domains in the in-plane $\left(L_{a}\right)$ and stacking $\left(L_{c}\right)$ directions, and (d) volume resistivity.

(a)

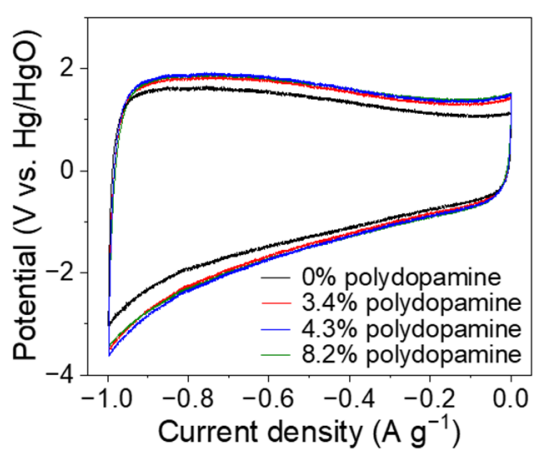

(c)

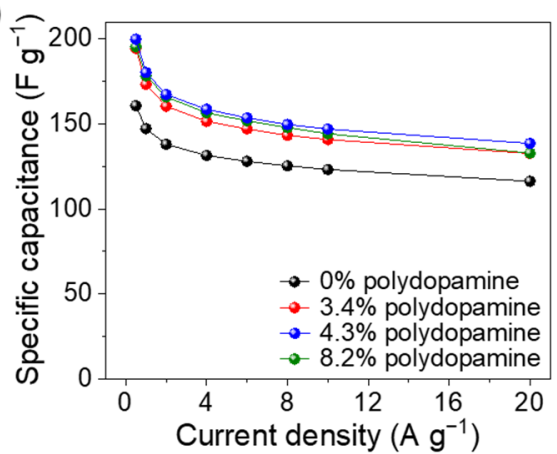

(b)

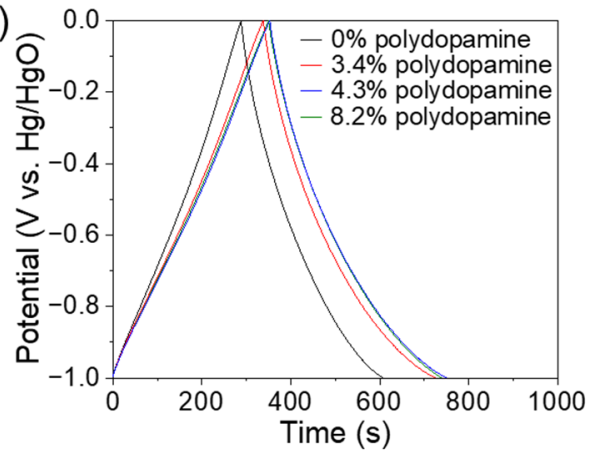

(d)

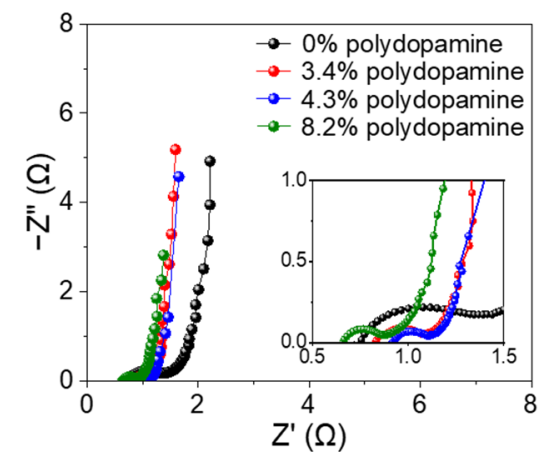

Figure 5. Electrochemical tests of the polydopamine-doped cellulose nanofiber papers pyrolyzed at $700^{\circ} \mathrm{C}$. (a) Cyclic voltammetry curves (scan rate: $10 \mathrm{mV} \mathrm{s}^{-1}$ ); (b) galvanostatic charge-discharge curves (current intensity: $0.5 \mathrm{~A} \mathrm{~g}^{-1}$ ); (c) specific capacitance at the current densities of $0.5-20 \mathrm{~A} \mathrm{~g}^{-1}$; (d) Nyquist plots. 
The mechanism that was responsible for the enhanced specific capacitance was discussed. Regardless of polydopamine doping, the pyrolyzed cellulose nanofiber papers presented a rectangular shape with distortion in the $\mathrm{CV}$ curves and slight nonlinear chargedischarge curves, which indicate an electric double-layer capacitor behavior with redox pseudocapacitance [47] (Figure 5a,b). The redox pseudocapacitance is derived from disordered carbon structures, such as oxygen- and nitrogen-containing groups [51], which can be estimated as the coulombic efficiency obtained from the ratio of the discharge duration to the charge duration in the charge-discharge curves [52]. The pyrolyzed cellulose nanofiber papers with polydopamine contents of $0,3.4,4.3$, and $8.2 \mathrm{wt} \%$ showed coulombic efficiencies of $111.11,114.64,112.96$, and $110.76 \%$ at $0.5 \mathrm{~A} \mathrm{~g}^{-1}$, respectively, indicating minimal difference in their redox pseudocapacitance. The resistance of electrolyte ion diffusion within the electrodes and the interfacial charge-transfer at the electrode-electrolyte interface was further analyzed by Nyquist plots, which consist of a linear line at low-frequency region and a semicircle at high-frequency region [47] (Figure 5d). The pyrolyzed cellulose nanofiber papers with and without polydopamine showed a nearly vertical line, representing efficient ionic diffusion [40], which is possibly due to their 3D porous nanostructures (Figure $3 \mathrm{e}-\mathrm{f}$ ). It has been reported that $\mathrm{K}^{+}$(electrolyte ion) with a large radius can cause the structural deformation of the electrode during the insertion and extraction processes $[53,54]$. In this study, however, the pyrolyzed polydopamine-doped cellulose nanofiber paper maintained its porous nanostructures after electrochemical tests (Figure S5). Notably, the pyrolyzed polydopamine-doped cellulose nanofiber papers showed a smaller diameter of a semicircle than that without polydopamine doping. This indicates a more efficient interfacial charge-transfer at the electrode-electrolyte interface [40] for the polydopaminedoped samples, owing to their higher electrical conductivity as electrodes (Figure 4d). Thus, the highest specific capacitance of the pyrolyzed $4.3 \mathrm{wt} \%$ polydopamine-doped cellulose nanofiber paper is a result of its enhanced electrical conductivity and high specific surface area (Figure 3j). Moreover, the pyrolyzed polydopamine-doped cellulose nanofiber paper provided higher specific capacitance than previously reported cellulose- and other biomass-derived porous nanocarbon materials such as carbonized cellulose aerogel [46], wood-derived carbon nanofiber aerogel [49], and hybrid nanocellulose derived hierarchical porous carbon film [55], suggesting its great potential as promising electrodes in supercapacitors (Table S1).

\section{Conclusions}

We have demonstrated that the polydopamine doping and pyrolysis of cellulose nanofiber paper can be a promising method that can be used to fabricate the 3D porous nanocarbons with improved carbon yield and volume retention. The pyrolyzed polydopamine-doped cellulose nanofiber paper also offered higher specific surface areas and electrical conductivity than that without polydopamine, thereby affording higher specific capacitance of up to $200 \mathrm{~F} \mathrm{~g}^{-1}$. The specific capacitance of the polydopamine-doped cellulose nanofiber paper was superior to the cellulose-derived nanocarbons that have been reported previously. Our results suggest that this method will facilitate the effective fabrication of high-performance cellulose-derived 3D porous nanocarbons for energy storage and other electronic applications. This method can be extended to other bionanomaterials, paving the way for future sustainable electronics.

Supplementary Materials: The following are available online at https:/ / www.mdpi.com/article/10 $.3390 /$ nano11123249/s1, Figure S1: Elemental content of cellulose nanofiber papers with varying dopamine content, Figure S2: Elemental content of the original and the polydopamine-doped cellulose nanofiber papers pyrolyzed at $700{ }^{\circ} \mathrm{C}$, Figure S3: Cross-sectional field emission scanning electron microscopy images of the original and the pyrolyzed cellulose nanofiber paper with different polydopamine content ( $0 \%$ and $4.3 \%$ ), Figure S4: Field emission scanning electron microscopy images of neat polydopamine, Figure S5: Field emission scanning electron microscopy images of electrode (pyrolyzed 4.3\% polydopamine-doped cellulose nanofiber paper) before and after electrochemical tests, Table S1: Specific capacitance values of cellulose-derived porous carbon materials. 
Author Contributions: Data curation, L.Z.; formal analysis, L.Z., K.U. and H.K.; funding acquisition, L.Z. and H.K.; investigation, L.Z.; methodology, L.Z. and H.K.; supervision, M.N.; writing-original draft, L.Z.; writing-Review and editing, K.U., M.N. and H.K. All authors have read and agreed to the published version of the manuscript.

Funding: This work was partially supported by Grant-in-Aid for JSPS fellow (JP20J11624 to L.Z.), and by "Nanotechnology Platform Project (Nanotechnology Open Facilities in Osaka University)" from the Ministry of Education, Culture, Sports, Science and Technology, Japan (No. JPMXP09S21OS0029 to H.K.), the Japan Prize Heisei Memorial Research Grant Program (H.K.), and the JST FOREST Program (JPMJFR2003 to H.K.).

Institutional Review Board Statement: Not applicable.

Informed Consent Statement: Not applicable.

Data Availability Statement: The data is included in the main text and/or the Supplementary Materials.

Acknowledgments: Luting Zhu thanks Tsuyoshi Matsuzaki, Comprehensive Analysis Center, SANKEN (The Institute of Scientific and Industrial Research), Osaka University, for the elemental analysis.

Conflicts of Interest: The authors declare no conflict of interest.

\section{References}

1. Zhang, L.; Shi, Y.; Wang, Y.; Shiju, N.R. Nanocarbon catalysts: Recent understanding regarding the active sites. Adv. Sci. 2020, 7, 1902126. [CrossRef]

2. Xin, S.; Guo, Y.; Wan, L. Nanocarbon networks for advanced rechargeable lithium batteries. Acc. Chem. Res. 2012, 45, 1759-1769. [CrossRef]

3. Mao, X.; Rutledge, G.C.; Hatton, T.A. Nanocarbon-based electrochemical systems for sensing, electrocatalysis, and energy storage. Nano Today 2014, 9, 405-432. [CrossRef]

4. Dutta, S.; Bhaumik, A.; Wu, K.C.-W. Hierarchically porous carbon derived from polymers and biomass: Effect of interconnected pores on energy applications. Energy Environ. Sci. 2014, 7, 3574-3592. [CrossRef]

5. Chen, L.; Feng, Y.; Liang, H.; Wu, Z.; Yu, S. Macroscopic-scale three-dimensional carbon nanofiber architectures for electrochemical energy storage devices. Adv. Energy Mater. 2017, 7, 1700826. [CrossRef]

6. Lv, T.; Liu, M.; Zhu, D.; Gan, L.; Chen, T. Nanocarbon-based materials for flexible all-solid-state supercapacitors. Adv. Mater. 2018, 30, 1705489. [CrossRef]

7. Liu, L.; Niu, Z.; Chen, J. Unconventional supercapacitors from nanocarbon-based electrode materials to device configurations. Chem. Soc. Rev. 2016, 45, 4340-4363. [CrossRef]

8. Tu, Y.; Deng, D.; Bao, X. Nanocarbons and their hybrids as catalysts for non-aqueous lithium-oxygen batteries. J. Energy Chem. 2016, 25, 957-966. [CrossRef]

9. Ma, L.; Li, J.; Li, Z.; Ji, Y.; Mai, W.; Wang, H. Ultra-stable potassium ion storage of nitrogen-doped carbon nanofiber derived from bacterial cellulose. Nanomaterials 2021, 11, 1130. [CrossRef] [PubMed]

10. Li, J.; Qin, W.; Xie, J.; Lei, H.; Zhu, Y.; Huang, W.; Xu, X.; Zhao, Z.; Mai, W. Sulphur-doped reduced graphene oxide sponges as high-performance free-standing anodes for K-ion storage. Nano Energy 2018, 53, 415-424. [CrossRef]

11. Titirici, M.-M.; White, R.J.; Brun, N.; Budarin, V.L.; Su, D.S.; del Monte, F.; Clark, J.H.; MacLachlan, M.J. Sustainable carbon materials. Chem. Soc. Rev. 2015, 44, 250-290. [CrossRef]

12. Inagaki, M.; Yang, Y.; Kang, F. Carbon nanofibers prepared via electrospinning. Adv. Mater. 2012, 24, 2547-2566. [CrossRef]

13. Spörl, J.M.; Beyer, R.; Abels, F.; Cwik, T.; Müller, A.; Hermanutz, F.; Buchmeiser, M.R. Cellulose-derived carbon fibers with improved carbon yield and mechanical properties. Macromol. Mater. Eng. 2017, 302, 1700195. [CrossRef]

14. Fox, B. Making stronger carbon-fiber precursors. Science 2019, 366, 1314-1315. [CrossRef]

15. Trache, D.; Thakur, V.K.; Boukherroub, R. Cellulose nanocrystals/graphene hybrids—a promising new class of materials for advanced applications. Nanomaterials 2020, 10, 1523. [CrossRef] [PubMed]

16. Rana, A.K.; Frollini, E.; Thakur, V.K. Cellulose nanocrystals: Pretreatments, preparation strategies, and surface functionalization. Int. J. Biol. Macromol. 2021, 182, 1554-1581. [CrossRef]

17. Xu, P.; Tong, J.; Zhang, L.; Yang, Y.; Chen, X.; Wang, J.; Zhang, S. Dung beetle forewing-derived nitrogen and oxygen self-doped porous carbon for high performance solid-state supercapacitors. J. Alloys Compd. 2022, 892, 162129. [CrossRef]

18. Wang, Z.; Zhang, X.; Liu, X.; Zhang, Y.; Zhao, W.; Li, Y.; Qin, C.; Bakenov, Z. High specific surface area bimodal porous carbon derived from biomass reed flowers for high performance lithium-sulfur batteries. J. Colloid Interface Sci. 2020, 569, 22-33. [CrossRef]

19. Zhang, Y.; Wu, C.; Dai, S.; Liu, L.; Zhang, H.; Shen, W.; Sun, W.; Li, C.M. Rationally tuning ratio of micro- to meso-pores of biomass-derived ultrathin carbon sheets toward supercapacitors with high energy and high power density. J. Colloid Interface Sci. 2022, 606, 817-825. [CrossRef] [PubMed] 
20. Zhan, Y.; Bai, J.; Guo, F.; Zhou, H.; Shu, R.; Yu, Y.; Qian, L. Facile synthesis of biomass-derived porous carbons incorporated with $\mathrm{CuO}$ nanoparticles as promising electrode materials for high-performance supercapacitor applications. J. Alloys Compd. 2021, 885, 161014. [CrossRef]

21. Li, T.; Chen, C.; Brozena, A.H.; Zhu, J.Y.; Xu, L.; Driemeier, C.; Dai, J.; Rojas, O.J.; Isogai, A.; Wågberg, L.; et al. Developing fibrillated cellulose as a sustainable technological material. Nature 2021, 590, 47-56. [CrossRef] [PubMed]

22. Yano, H.; Sasaki, S.; Shams, I.; Abe, K.; Date, T. Wood pulp-based optically transparent film: A paradigm from nanofibers to nanostructured fibers. Adv. Opt. Mater. 2014, 2, 231-234. [CrossRef]

23. Abe, K.; Iwamoto, S.; Yano, H. Obtaining cellulose nanofibers with a uniform width of $15 \mathrm{~nm}$ from wood. Biomacromolecules 2007, 8, 3276-3278. [CrossRef]

24. Saito, T.; Kimura, S.; Nishiyama, Y.; Isogai, A. Cellulose nanofibers prepared by TEMPO-mediated oxidation of native cellulose. Biomacromolecules 2007, 8, 2485-2491. [CrossRef] [PubMed]

25. Kondo, T.; Kose, R.; Naito, H.; Kasai, W. Aqueous counter collision using paired water jets as a novel means of preparing bio-nanofibers. Carbohydr. Polym. 2014, 112, 284-290. [CrossRef]

26. Toivonen, M.S.; Kaskela, A.; Rojas, O.J.; Kauppinen, E.I.; Ikkala, O. Ambient-dried cellulose nanofibril aerogel membranes with high tensile strength and their use for aerosol collection and templates for transparent, flexible devices. Adv. Funct. Mater. 2015, 25, 6618-6626. [CrossRef]

27. Koga, H.; Namba, N.; Takahashi, T.; Nogi, M.; Nishina, Y. Renewable wood pulp paper reactor with hierarchical micro/nanopores for continuous-flow nanocatalysis. ChemSusChem 2017, 10, 2560-2565. [CrossRef]

28. Frank, E.; Steudle, L.M.; Ingildeev, D.; Spörl, J.M.; Buchmeiser, M.R. Carbon fibers: Precursor systems, processing, structure, and properties. Angew. Chem. Int. Ed. 2014, 53, 5262-5298. [CrossRef]

29. Cho, D.; Kim, J.M.; Kim, D. Phenolic resin infiltration and carbonization of cellulose-based bamboo fibers. Mater. Lett. 2013, 104, 24-27. [CrossRef]

30. Barron, A.B.; Søvik, E.; Cornish, J.L. The roles of dopamine and related compounds in reward-seeking behavior across animal phyla. Front. Behav. Neurosci. 2010, 4, 163. [CrossRef]

31. Wang, Y.; Zhu, L.; You, J.; Chen, F.; Zong, L.; Yan, X.; Li, C. Catecholic coating and silver hybridization of chitin nanocrystals for ultrafiltration membrane with continuous flow catalysis and gold recovery. ACS Sustain. Chem. Eng. 2017, 5, 10673-10681. [CrossRef]

32. Jiang, Q.; Derami, H.G.; Ghim, D.; Cao, S.; Jun, Y.S.; Singamaneni, S. Polydopamine-filled bacterial nanocellulose as a biodegradable interfacial photothermal evaporator for highly efficient solar steam generation. J. Mater. Chem. A 2017, 5, 18397-18402. [CrossRef]

33. Zeng, L.; Zhao, S.; He, M. Macroscale porous carbonized polydopamine-modified cotton textile for application as electrode in microbial fuel cells. J. Power Sources 2018, 376, 33-40. [CrossRef]

34. Zhu, L.; Huang, Y.; Morishita, Y.; Uetani, K.; Nogi, M.; Koga, H. Pyrolyzed chitin nanofiber paper as a three-dimensional porous and defective nanocarbon for photosensing and energy storage. J. Mater. Chem. C 2021, 9, 4444-4452. [CrossRef]

35. Fukuzumi, H.; Saito, T.; Okita, Y.; Isogai, A. Thermal stabilization of TEMPO-oxidized cellulose. Polym. Degrad. Stab. 2010, 95, 1502-1508. [CrossRef]

36. Cho, J.H.; Vasagar, V.; Shanmuganathan, K.; Jones, A.R.; Nazarenko, S.; Ellison, C.J. Bioinspired catecholic flame retardant nanocoating for flexible polyurethane foams. Chem. Mater. 2015, 27, 6784-6790. [CrossRef]

37. Shanmuganathan, K.; Cho, J.H.; Iyer, P.; Baranowitz, S.; Ellison, C.J. Thermooxidative stabilization of polymers using natural and synthetic melanins. Macromolecules 2011, 44, 9499-9507. [CrossRef]

38. Zhang, C.; Chao, L.; Zhang, Z.; Zhang, L.; Li, Q.; Fan, H.; Zhang, S.; Liu, Q.; Qiao, Y.; Tian, Y.; et al. Pyrolysis of cellulose: Evolution of functionalities and structure of bio-char versus temperature. Renew. Sustain. Energy Rev. 2021, 135, 110416. [CrossRef]

39. Zhang, X.; Ma, L.; Gan, M.; Fu, G.; Jin, M.; Lei, Y.; Yang, P.; Yan, M. Fabrication of 3D lawn-shaped N-doped porous carbon matrix/polyaniline nanocomposite as the electrode material for supercapacitors. J. Power Sources 2017, 340, 22-31. [CrossRef]

40. Gao, L.; Xiong, L.; Xu, D.; Cai, J.; Huang, L.; Zhou, J.; Zhang, L. Distinctive construction of chitin-derived hierarchically porous carbon microspheres/polyaniline for high-rate supercapacitors. ACS Appl. Mater. Interfaces 2018, 10, 28918-28927. [CrossRef]

41. Biscoe, J.; Warren, B.E. An X-ray study of carbon black. J. Appl. Phys. 1942, 13, 364-371. [CrossRef]

42. Jurkiewicz, K.; Pawlyta, M.; Burian, A. Structure of carbon materials explored by local transmission electron microscopy and global powder diffraction probes. J. Carbon Res. 2018, 4, 68. [CrossRef]

43. Tanaka, K.; Ueda, M.; Koike, T.; Yamabe, T. X-ray diffraction studies of pristine and heavily-doped polyacenic materials. Synth. Met. 1988, 25, 265-275. [CrossRef]

44. Liu, Q.; Jing, S.; Wang, S.; Zhuo, H.; Zhong, L.; Peng, X.; Sun, R. Flexible nanocomposites with ultrahigh specific areal capacitance and tunable properties based on a cellulose derived nanofiber-carbon sheet framework coated with polyaniline. J. Mater. Chem. A 2016, 4, 13352-13362. [CrossRef]

45. Liang, H.W.; Wu, Z.Y.; Chen, L.F.; Li, C.; Yu, S.H. Bacterial cellulose derived nitrogen-doped carbon nanofiber aerogel: An efficient metal-free oxygen reduction electrocatalyst for zinc-air battery. Nano Energy 2015, 11, 366-376. [CrossRef]

46. Li, X.; Zhang, Y.; Zhang, J.; Wang, C. Isolated Fe atoms dispersed on cellulose-derived nanocarbons as an efficient electrocatalyst for the oxygen reduction reaction. Nanoscale 2019, 11, 23110-23115. [CrossRef] 
47. Cai, J.; Niu, H.; Li, Z.; Du, Y.; Cizek, P.; Xie, Z.; Xiong, H.; Lin, T. High-performance supercapacitor electrode materials from cellulose-derived carbon nanofibers. ACS Appl. Mater. Interfaces 2015, 7, 14946-14953. [CrossRef] [PubMed]

48. Tian, X.; Zhu, S.; Peng, J.; Zuo, Y.; Wang, G.; Guo, X.; Zhao, N.; Ma, Y.; Ma, L. Synthesis of micro- and meso-porous carbon derived from cellulose as an electrode material for supercapacitors. Electrochim. Acta 2017, 241, 170-178. [CrossRef]

49. Li, S.C.; Hu, B.C.; Ding, Y.W.; Liang, H.W.; Li, C.; Yu, Z.Y.; Wu, Z.Y.; Chen, W.S.; Yu, S.H. Wood-derived ultrathin carbon nanofiber aerogels. Angew. Chem. Int. Ed. 2018, 57, 7085-7090. [CrossRef]

50. Xu, X.; Shen, J.; Li, F.; Wang, Z.; Zhang, D.; Zuo, S.; Liu, J. $\mathrm{Fe}_{3} \mathrm{O}_{4} @ \mathrm{C}$ Nanotubes Grown on Carbon Fabric as a Free-Standing Anode for High-Performance Li-Ion Batteries. Chem. A Eur. J. 2020, 26, 14708-14714. [CrossRef] [PubMed]

51. Pang, J.; Zhang, W.; Zhang, H.; Zhang, J.; Zhang, H.; Cao, G.; Han, M.; Yang, Y. Sustainable nitrogen-containing hierarchical porous carbon spheres derived from sodium lignosulfonate for high-performance supercapacitors. Carbon 2018, 132, 280-293. [CrossRef]

52. Xia, X.; Hao, Q.; Lei, W.; Wang, W.; Wang, H.; Wang, X. Reduced-graphene oxide/molybdenum oxide/polyaniline ternary composite for high energy density supercapacitors: Synthesis and properties. J. Mater. Chem. 2012, 22, 8314-8320. [CrossRef]

53. Li, J.; Zhuang, N.; Xie, J.; Zhu, Y.; Lai, H.; Qin, W.; Javed, M.S.; Xie, W.; Mai, W. Carboxymethyl cellulose binder greatly stabilizes porous hollow carbon submicrospheres in capacitive K-Ion storage. ACS Appl. Mater. Interfaces 2019, 11, 15581-15590. [CrossRef] [PubMed]

54. Xu, X.; Mai, B.; Liu, Z.; Ji, S.; Hu, R.; Ouyang, L.; Liu, J.; Zhu, M. Self-sacrificial template-directed ZnSe@C as high performance anode for potassium-ion batteries. Chem. Eng. J. 2020, 387, 124061. [CrossRef]

55. Li, Z.; Ahadi, K.; Jiang, K.; Ahvazi, B.; Li, P.; Anyia, A.O.; Cadien, K.; Thundat, T. Freestanding hierarchical porous carbon film derived from hybrid nanocellulose for high-power supercapacitors. Nano Res. 2017, 10, 1847-1860. [CrossRef] 